\title{
Research Paper: Effectiveness of Group Training of Mindfulness-Based Techniques on Improvement of cross Psychological Well-Being of Individuals With Spinal Cord Injury
}

\author{
Reza Abdi ${ }^{*}$, Esmail Kheyrjoo ${ }^{2}$, Somayeh Javidfar ${ }^{3}$, Golnaz Jabari ${ }^{4}$
}

1. Assistant Professor, Department of Psychology, Faculty of Education and Psychology, Azarbaijan Shahid Madani University, Tabriz. Iran.

2. Assistant Professor, Department of Family Studies, Faculty of Education and Psychology, Azarbaijan Shahid Madani University, Tabriz. Iran.

3. MA in Clinical Psychology, East Azarbaijan Welfare Organization, Tabriz, Iran.

4. MA in Clinical Psychology, Department of Psychology, Faculty of Education and Psychology, Azarbaijan Shahid Madani University, Tabriz. Iran

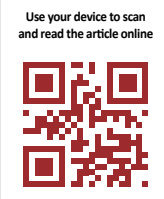

Citation: Abdi R, Kheyrjoo E, Javidfar S, Jabari G. Effectiveness of Group Training of Mindfulness-Based Techniques on Improvement of Psychological Well-Being of Individuals With Spinal Cord Injury. Journal of Modern Rehabilitation. 2016; 10(4):155-162. https://doi.org/10.18869/nirp.jmr.10.4.155

https://doi.org/10.18869/nirp.jmr.10.4.155

Article info:

Received: 08 Jun. 2016

Revised: 13 Aug. 2016

Accepted: 02 Sep. 2016

\section{Keywords:}

Psychological well-being, Mindfulness, Spinal cord injury

\section{ABSTRACT}

Introduction: The present study aimed to investigate the effectiveness of group training of mindfulness-based techniques on improvement of psychological well-being of patients with Spinal Cord Injury (SCI) covered by Tabriz Rehabilitation Organization.

Material and Methods: To this aim, 30 patients with SCI were selected by cluster random sampling out of paralyzed people due to SCI from centers covered by Tabriz Welfare Organization. Then, they were randomly assigned to experimental $(n=15)$ and control group $(\mathrm{n}=15)$. The experimental group received 8 sessions of mindfulness training, but the control group received no intervention. Both groups completed psychological well-being scale of Ryff as well as demographic questionnaire before and after the intervention.

Results: Result of covariance analysis showed that mindfulness training affected improvement of self-acceptance $(\mathrm{F}=31.55, \mathrm{P}<0.001)$, establishment of quality ties to others $(\mathrm{F}=31.55$, $\mathrm{P}<0.001)$, a sense of autonomy $(\mathrm{F}=231.87, \mathrm{P}<0.001)$, ability to manage complex environments $(\mathrm{F}=121.64, \mathrm{P}<0.001)$, pursuit meaningful goals $(\mathrm{F}=212.15, \mathrm{P}<0.001)$, continued growth and development as a person $(\mathrm{F}=747.09, \mathrm{P}<0.001)$, and total score of psychological well-being $(\mathrm{F}=1212.83, \mathrm{P}<0.001)$ of patients with $\mathrm{SCI}$.

Conclusion: The findings supported the effectiveness of mindfulness training on improvement of psychological well-being of patients with SCI, and such changes may occur due to mediating the role of recognition mechanism.

* Corresponding Author:

Reza Abdi, PhD

Address: Department of Psychology, Faculty of Education and Psychology, Azarbaijan Shahid Madani University, Tabriz, Iran.

Tel: +98 (914) 4007477

E-mail:rabdi@azaruniv.ac.ir 


\section{Introduction}

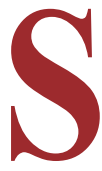

pinal Cord Injury (SCI) is a congenital condition (Myelomeningocele) or results from some lesions (trauma, accidents, falling of height, disk operation, and spinal tumor). It invariably affects victim's physical, social, and psychological aspects so that the person's normal life may totally change [1]. The incidence of SCI around the world varies between 20 and 50 per million people while in Iran 1800 to 2400 people are annually affected by SCI according to SCI Research Center report. This figure is considered a very high rate in comparison to other countries [2].

Disability affects not only the injured patient but also first degree relatives and family members. Many individuals with SCI suffer from a feeling of inferiority, depression, low self-esteem, family problems, anger, rejection by others, marital problems, less satisfaction of life, and limited occupational and recreational activities [3-5]. An important issue in this field is the association between physical and mental problems, which may intensify problems of these people. Research indicates high incidence of health problems such as depression [6], suicidal ideations, psychological well-being [7], and psychological disorders such as anxiety disorders, depression, and alcohol abuse [8] among people with SCI.

Migliorini and Tonge after extensive study concluded that people with SCI are not affected by objective wellbeing instead by perceived or subjective psychological well-being. Subjective or psychological well-being with respect to different concepts of health definition is recognized as cognitive and emotional evaluation of the totality of life [9]. According to this definition of wellbeing, health is not just absence of disease but consists of rich and purposeful life, ability to solve problems and adapt to social environment, and having meaningful life [10]. Psychological well-being includes experience of physical and emotional pain along with favorite and effective performance besides positive emotions with a sense of empowerment. The concept of psychological well-being monitors feeling of well-being, self-efficacy, self-reliance, capacity, competition, self-actualization of intellectual, and emotional potentials [11].

The World Health Organization recognizes psychological well-being as the ability to have balanced relationship with others, ability to modify the social environment, appropriate and reasonable solving of conflicts that will improve the growth and perfection of the human personality and helping people to adapt with them- selves and others, in short its main purpose is helping all people to achieve perfect, happy, balanced and widespread recognition and avoid emotional, behavioral, and mood disorders [12].

Mindfulness-based intervention is one of the relatively new interventions that its effectiveness on various aspects of health and psychological problems within different groups are studied. Mindfulness means paying attention to the present moment in a particular and objective way without prior judgment [13]. Mindfulness is defined as the arousal attention and awareness of what is happening at the present moment $[14,15]$. According to Baer (2004), mindfulness is not a technique or method instead a way of understanding the personal feeling [16]. Our minds often interpret events that may result in reactions and lasting impressions, but mindfulness is a skill that allows us experience events and feeling less than their real painfulness and when we are aware of the present moment, our attention will not involve in the past and future while more mental health problems are due to focus on past events [17]. Useful coping strategies of mindfulness for creating and maintaining awareness include lack of judgment, patience, primers mind, not involving, and openness [18].

There are numerous studies on the effectiveness of mindfulness-based interventions in various fields, including psychological well-being of different population groups [14, 19-21] and also some studies have shown that psychological problems like depression in patients with SCI have negative correlation with the skill of mindfulness and acceptance [22]. However, there are no substantial studies for effectiveness of mindfulness training on psychological problems of patients with SCI. So this research examined the effectiveness of mindfulnessbased intervention on improving psychological wellbeing of patients with SCI.

\section{Materials and Methods}

\section{Research design}

The present study is quasi-experimental with pretestposttest and a control group. Statistical population included all disabled people suffered from SCI who were supported by Tabriz Welfare Organization from October to August of 2015. Research sample consisted of all spinal cord injury disabled covered by two SCI rehabilitation centers as the two clusters that were selected by 1-stage cluster random sampling method out of total 5 SCI rehabilitation centers of Tabriz Welfare Organization. Then, the participants were randomly assigned to 
experimental and control groups. However, during the intervention, participants number dropped to 15 for each group. Sample size of this research was determined by considering research method textbooks that commented on at least 15 participants to each group in interventional studies [23]. The inclusion criteria were as follows: 1) being adult and aged 18 years or older, 2) having spinal cord injuries, 3) being supported by Tabriz Welfare Organization, and 4) being educated up to high school. The exclusion criteria were as follows: 1) being under medication for any psychological disorder during the intervention period, 2) having history of psychotherapy for over 2 years, 3 ) having other neurological diseases, cognitive deficits or mental disorders, and 4) being educated under high school.

\section{Measures}

\section{Psychological well-being scale of ryff}

This scale was designed in 1980 [24]. Original form had 120 items. However it has a short form which its 84item version was used. Psychological well-being scale has 6 subscales: self-acceptance, positive relationship with others, autonomy, purposeful life, personal growth and domination on the environment. In 84-item form, each subscale has 14 questions that were rated based on 6-point Likert-type scale from completely disagree to completely agree. The minimum and maximum scores for each subscale were 14 and 84, respectively [24].

Reliability was calculated by test-retest method and were reported as $0.70,0.77,0.78,0.77,0.71,0.87$ correlation coefficients for self-acceptance, establishment of quality ties to other, a sense of autonomy, ability to manage complex environments, pursuit of meaningful goals, continued growth and development as a person, respectively [25]. Mikaeily (2010) studied Persian version of the questionnaire and confirmed its validity. To test reliability, the Cronbach $\alpha$ was used, which was 0.87 for the whole questionnaire and higher than 0.7 for each component [25].

\section{Study Procedure}

After coordination with authorities of Welfare Organization of Tabriz, participants were selected from two rehabilitation centers and their families completed written informed consent forms. After selecting participants they were randomly assigned into experimental and control groups, and psychological well-being questionnaire was administered to both groups. Intervention program was conducted during 8 weekly sessions based on Segal et al. Mindfulness-Based Cognitive Therapy (MBCT) [26] protocol on experimental group by the corresponding author who had license and qualifications in the field of mindfulness-based intervention. At the end of intervention, the questionnaires were completed by both groups (Table 1).

\section{Data analysis}

Descriptive indexes, including mean and standard deviation of demographical and research variables as well as ensuring about statistical assumption of normality (by Kolmogorov-Smirnov Test) and homogeneity of variance (by Levene's Test) were calculated for each variable. To test intervention effect between groups,

Table 1. The content of intervention sessions

\begin{tabular}{|c|c|}
\hline Session & Content \\
\hline 1 & $\begin{array}{c}\text { Explaining general outlines and objectives and how the classes will be held, as well as importance of pres- } \\
\text { ence in the present moment, clarification of logic of effect of mindfulness and concept of mindfulness for } \\
\text { members. }\end{array}$ \\
\hline 2 & Recognition of wander mind and doing practices for focusing attention on body and breath. \\
\hline 3 & $\begin{array}{c}\text { Relaxing wander mind by breathing exercises and checking body, sitting meditation and exercises that } \\
\text { brings focus into the present moment. }\end{array}$ \\
\hline 4 & $\begin{array}{l}\text { The relaxation training and learning being in the present moments without running away from negative } \\
\text { events, thoughts and emotions to monitor changes of thoughts. }\end{array}$ \\
\hline 5 & Full awareness of thoughts and feelings and accepting them without judgment and direct involvement. \\
\hline 6 & Changing moods and thoughts through considering mind as thoughts and not as a reality. \\
\hline 7 & Awareness of symptoms of anxiety and set up a program to deal with anxiety and disability. \\
\hline 8 & Planning for the future and use of mindfulness in life and generalization in different situations. \\
\hline
\end{tabular}


data obtained from Ryff questionnaire of psychological well-being were analyzed by 1-way analysis of covariance (ANCOVA) and pretest scores in each component of psychological well-being was used as covariate. For data analysis SPSS 19 was used.

\section{Results}

The experimental group comprised 15 participants (11 males and 4 females, mean $[\mathrm{SD}]$ age $=27$ [43.6]) and the control group were 15 participants (11 males and 4 females, mean $[\mathrm{SD}]$ age $=27.26[6.17])$

Descriptive statistics of research variables with its components for both experimental and control groups in the pretest and posttest phases are presented in Table 2. In order to examine the effectiveness of mindfulness on each component and total score of psychological wellbeing, covariance analysis was used that its results are presented in Table 3. According to the Table, for effec-

Table 2. Descriptive statistics of psychological well-being and its components

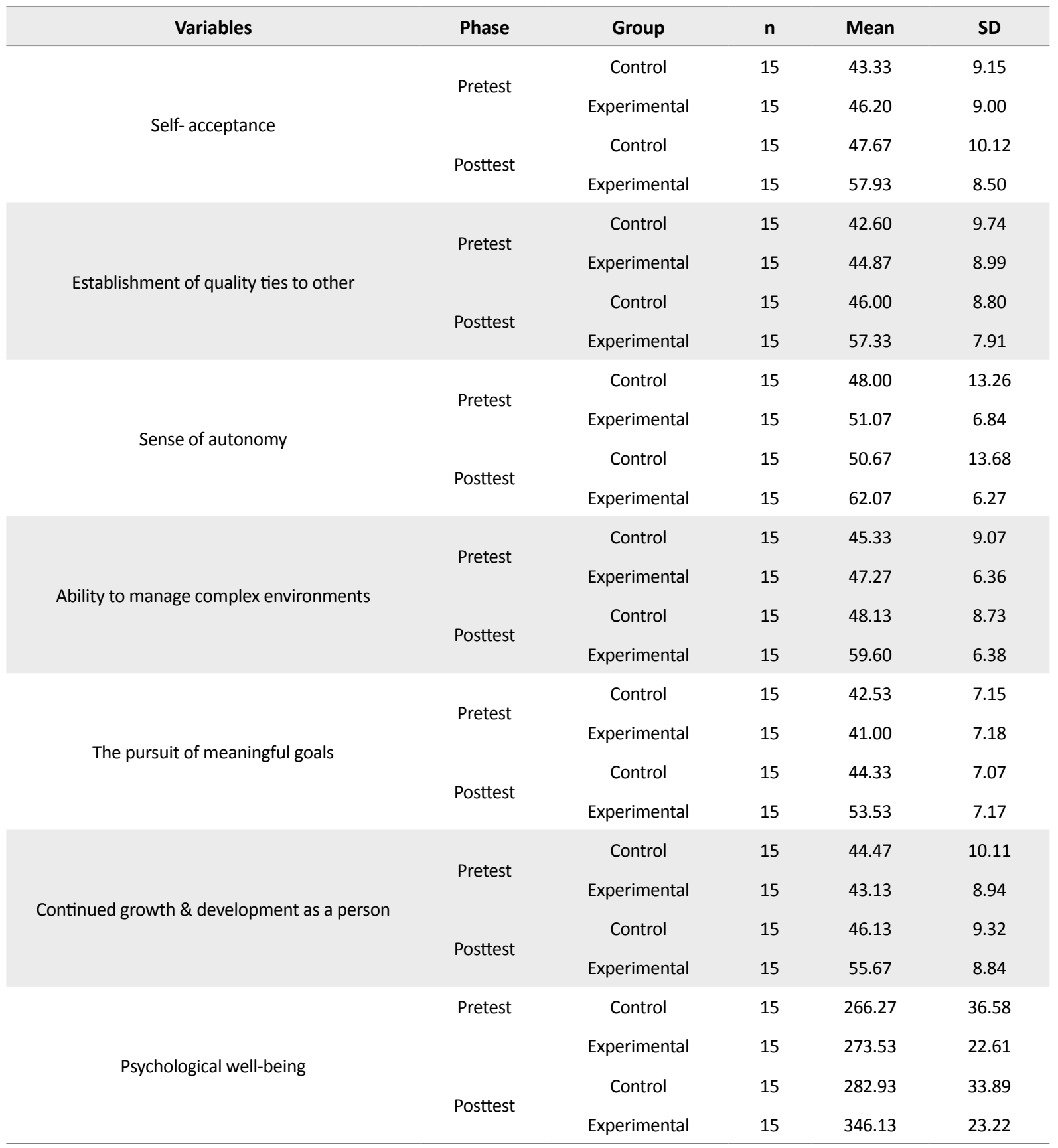


Table 3. Results of covariance analysis of effectiveness of mindfulness on psychological well-being and its components

\begin{tabular}{|c|c|c|c|c|c|}
\hline Variable & Source & df & $\mathbf{F}$ & Sig. & Eta \\
\hline & Pretest & 1 & 159.04 & 0.001 & 0.54 \\
\hline \multirow[t]{3}{*}{ Self-acceptance } & Group & 1 & 31.55 & 0.001 & 0.41 \\
\hline & Error & 27 & & & \\
\hline & Pretest & 1 & 678.34 & 0.001 & 0.96 \\
\hline \multirow[t]{3}{*}{ Establishment of quality ties to other } & Group & 1 & 231.87 & 0.001 & 0.89 \\
\hline & Error & 27 & & & \\
\hline & Pretest & 1 & 531.28 & 0.001 & 0.95 \\
\hline \multirow[t]{3}{*}{ Sense of autonomy } & Group & 1 & 87.67 & 0.001 & 0.76 \\
\hline & Error & 27 & & & \\
\hline & Pretest & 1 & 261.63 & 0.001 & 0.91 \\
\hline \multirow[t]{3}{*}{ Ability to manage complex environments } & Group & 1 & 121.64 & 0.001 & 0.82 \\
\hline & Error & 27 & & & \\
\hline & Pretest & 1 & 330.25 & 0.001 & 0.92 \\
\hline \multirow[t]{3}{*}{ The pursuit meaningful goals } & Group & 1 & 212.14 & 0.001 & 0.88 \\
\hline & Error & 27 & & & \\
\hline & Pretest & 1 & 1959.33 & 0.001 & 0.98 \\
\hline \multirow[t]{3}{*}{ Continued growth and development as a person } & Group & 1 & 747.09 & 0.001 & 0.96 \\
\hline & Error & 27 & & & \\
\hline & Pretest & 1 & 1195.51 & 0.000 & 0.98 \\
\hline \multirow[t]{2}{*}{ Total scores of psychological well-being } & Group & 1 & 1212.83 & 0.001 & 0.98 \\
\hline & Error & 27 & & & \\
\hline
\end{tabular}

Covariate: Pretest scores of psychological well-being components $\mathrm{P}<0.01$

tiveness of mindfulness on increasing "self-acceptance", pretest had significant effects on posttest $(\mathrm{P}<0.01)$. However, excluding the effect of pretest, group effects on posttest was significant $(\mathrm{P}<0.01)$ and indicated the effectiveness of mindfulness training on "self- acceptance" in patients with SCI.

Also regarding the "appropriate behavior with others", pretest had significant effects on posttest, also the group effects on posttest was significant $(\mathrm{P}<0.01)$ and posttest scores of experimental group in "appropriate behavior with others" increased. Results of covariance analysis of effectiveness of mindfulness on sense of "autonomy" revealed that effect of pretest and group effects $(\mathrm{P}<0.01)$ were significant and there were differences between posttest results of both groups regarding "sense of autonomy."

Results of "ability to manage complex environments" showed that pretest had significant effects on posttest $(\mathrm{P}<0.01)$. However, excluding the effect of pretest, there was significant differences between two groups $(\mathrm{P}<0.01)$ indicating increasing scores of experimental group in posttest compared to the control group. Results of covariance analysis of "the pursuit meaningful goals" showed that despite significance of pretest effects $(\mathrm{P}<0.01)$, there was significant difference between two group in posttest.

Finally, results of covariance analysis of "continued growth and development as a person" suggest that pretest 
had significant effects on posttest $(\mathrm{P}<0.01)$. However, excluding effect of pretest, there was significant differences between two groups $(\mathrm{P}<0.01)$ in "continued growth and development as a person." In addition to components, covariance analysis was done for psychological well-being and its results showed that effect of pretest and group effects $(\mathrm{P}<0.01)$ were significant also there was differences between posttests of both groups in psychological well-being. In sum, in all components and total score of psychological well-being, covariance analysis shows that the difference among the adjusted mean of posttest participant's scores in experimental and control groups were statistically significant. Therefore mindfulness skills had positive effects in improving psychological well-being of cases with spinal cord injury in Tabriz.

\section{Discussion}

This present study evaluated the effectiveness of mindfulness techniques on improvement of psychological well-being of patients with SCI in Tabriz. The obtained results showed that the scores of posttest of experimental group compared with the control group were higher than pretest in all components and total score of psychological well-being increased after intervention, suggesting the effectiveness of mindfulness techniques on the psychological well-being of patients with SCI. As earlier mentioned, to the best of our knowledge, there is no study about the effectiveness of mindfulness techniques on psychological well-being on patients with SCI and the only study by Finlay has not been published yet [27].

However, there are studies on the effectiveness of the mindfulness intervention on psychological problems and well-being of other groups that are consistent with our findings [14, 19, 20, 21, 26]. Carmody et al. (2006) examined impact of mindfulness training on various aspects of health and concluded that receiving 8 sessions of mindfulness-based intervention may improve psychological status such as reducing psychological distress and even physical symptoms [19]. Also, Keng and colleagues (2011) reviewed the studies on the effectiveness of mindfulness on different aspects of mental health. They examined more than 50 studies in this area and concluded that mindfulness can improve and facilitate the adaptive psychological functioning, may increase subjective psychological well-being, may reduce symptoms, and improves adjustment of appropriate behavior [28].

Brown and Ryan have also shown that mindfulness training and living at the present moment may improve psychological well-being of patients with cancer. Several studies in Iran reported similar findings on the im- pact of mindfulness on health and well-being of different groups. For example, Kazemian (2014) reported that mindfulness skills improved public health of addicts. Jahangir Pour and colleagues (2013) showed that mindfulness training reduced the symptoms of depression, hostility, and anxiety in patients with coronary heart disease and increased people's well-being. According to Baer (2003) mindfulness can be defined as a way of "being" or a way of "understanding" that requires understanding of personal emotions. Mindfulness is a better way of communication with life that can alleviate physical pain and enrich life through adapting experiences of every moment and providing direct insight on the role of the mind in creating undue anxiety [29].

Therefore, it increases the well-being, self-esteem, optimism, positive emotions and decreases anxiety, depression, negative affects, and psychological symptoms. The results showed that with mindfulness training, it is possible to increase psychological well-being. Mindfulness makes experiences clear and also teaches people to experience every moment of life so negative psychological symptoms will be decreased and psychological wellbeing will be increased. Shapiro, Carlson, Astin, and Freedman [30] studied how mindfulness affects psychological status and changes physical pain. They pointed out that using mindfulness skills may change person's views. According to them, deliberate attention with openness and monitoring without judgment may lead to significant change in views that is called "re-perceiving." This change in perception or view will result in changes in the psychological aspects, including cognitive, emotional and behavioral flexibility as well as tracking valuable parts of life.

Based on this mechanism, one realizes that pain, discomfort, and disappointing thoughts are not one's own, and therefore one is able to view them from different points of view. That reduces maladaptive behaviors and habits; such process is similar to projective process suggested by Hayes, Strosahl, Wilson, and Linhan [31, 32]. Perhaps it is due to such mechanism that people with SCI in experimental group got higher scores in self-acceptance after training. In addition to the direct impact of this mechanism on the improvement of flexibility, especially the impact of underlying mechanisms, mindfulness may recognize value or what is important in life and tries to achieve them, despite physical limitations. In fact, it might be concluded that increased ability to recognize the value through mindfulness help people with SCI put themselves in a better position in terms of sense of autonomy, ability to manage complex environments, meaningful life, and continued growth and development 
as a person. In other words, patients with SCI because of their cognitive abilities and moving along with values will be able to establish better relationships with others, the sense of efficacy and feel more satisfaction and purposeful life.

The research limitations must be considered in interpreting its results. First, its limited sample size; second, use of self-report to evaluate intervention effects on participants; and finally weak cooperation of some participants between session assignments and practices. Given that this study is one of the first studies on the effectiveness of mindfulness on improvement of psychological well-being, so more studies on the effectiveness of mindfulness on the different aspects of problems with SCI are required. It is recommended that future studies evaluate continuity of therapeutic effects through follow up.

\section{Acknowledgements}

This research did not receive any specific grant from funding agencies in the public, commercial, or not-for-profit sectors. We appreciate all participants, their families and those who helped us in conducting the present study, specially East Azarbaijan Welfare Organization Cooperation.

\section{Conflict of Interest}

The authors declared no conflicts of interest.

\section{References}

[1] Moghadam M, Habibi R, Davatgaran K, Nazmdeh K. [Comprehensive rehabilitation of spinal cord injury (Persian)]. Tehran: Welfare Organization of Iran; 2007.

[2] Kahrazie F, Mirshekar T. [Effect of wives group training on activities of daily living and quality of life in male patients with spinal cord injury (Persian)]. Medical - Surgical Nursing Journal. 2015; 4(1):54-9.

[3] Liu C-W, Attar KH, Gall A, Shah J, Craggs M. The relationship between bladder management and health-related quality of life in patients with spinal cord injury in the UK. Spinal Cord. 2009; 48(4):319-24. doi: 10.1038/sc.2009.132

[4] Karbalai Esmaili S, Modiran E, Mousavi B, Javadi Parvaneh M. [Participation and satisfaction after spinal cord injury: results of a vocational, marriage and leisure outcome study in Iranian victim females after spinal cord injury (Persian)]. Journal of Teb-e-Janbaz. 2009; 1(2):65-72

[5] Yousefpoor M, Garvosi MT. [The effect of life skills training on mental health, social performance and depression of physical disabilities of Tabriz city (Persian)]. Woman and Family Studies. 2009; 1(3):123-37.
[6] Williams R, Murray A. Prevalence of depression after spinal cord injury: A meta-analysis. Archives of Physical Medicine and Rehabilitation. 2015; 96(1):133-40. doi: 10.1016/j. apmr.2014.08.016

[7] McCullumsmith CB, Kalpakjian CZ, Richards JS, Forchheimer M, Heinemann AW, Richardson EJ, et al. Novel risk factors associated with current suicidal ideation and lifetime suicide attempts in individuals with spinal cord injury. Archives of Physical Medicine and Rehabilitation. 2015 96(5):799-808. doi: 10.1016/j.apmr.2014.12.017

[8] Craig A, Nicholson Perry K, Guest R, Tran Y, Dezarnaulds A, Hales A, et al. Prospective study of the occurrence of psychological disorders and comorbidities after spinal cord injury. Archives of Physical Medicine and Rehabilitation. 2015, 96(8):1426-34. doi: 10.1016/j.apmr.2015.02.027

[9] Migliorini C, Tonge B. Reflecting on subjective well-being and spinal cord injury. Journal of Rehabilitation Medicine. 2009; 41(6):445-50. doi: 10.2340/16501977-0358

[10] Diener E, Oishi S, Lucas RE. Personality, culture, and subjective well-being: Emotional and cognitive evaluations of Life. Annual Review of Psychology. 2003; 54(1):403-25. doi: 10.1146/annurev.psych.54.101601.145056

[11] DienerE, OishiS, Lucas R. Subjective well-being: The science of happiness and life satisfaction. Oxford: Oxford University Press; 2009. doi: 10.1093/oxfordhb/9780195187243.013.0017

[12] Hadadi Koohsar AA, Rooshan R \&, Asgharnejad FArid AA. [Comparision between emotional intelligence and mental health of students with their family relationships (Persian)] Journal of Modern Psychological Research. 2006; 1(4):69-87.

[13] Kaviani H, Hatami N, Shafiabadi A. [Mindfulness-based Cognitive Therapy (MBCT) reduces depression and anxiety induced by real stressful setting in non-clinical population (Persian)]. International Journal of Psychology and Psychological Therapy. 2011; 11(2):285-296.

[14] Brown KW, Ryan RM. The benefits of being present: Mindfulness and its role in psychological well-being. Journal of Personality and Social Psychology. 2003; 84(4):822-48. doi: 10.1037/0022-3514.84.4.822

[15] Walsh JJ, Balint MG, Smolira SJ DR, Fredericksen LK, Madsen S. Predicting individual differences in mindfulness: The role of trait anxiety, attachment anxiety and attentional control. Personality and Individual Differences. 2009; 46(2):94-9. doi: $10.1016 /$ j.paid.2008.09.008

[16] Baer RA. Mindfulness training as a clinical intervention A conceptual and empirical review. Clinical Psychology: Science and Practice. 2003; 10(2):125-43. doi: 10.1093/clipsy/ bpg015

[17] Kabat-Zinn J. Coming to our senses: Healing ourselves and the world through mindfulness. New York: Hyperion; 2005.

[18] Golpour R, Mohammad Amin Z. [The effectiveness of mindfulness-based stress reduction and increasing self-expression in student with exam anxiety (Persian)]. Journal of School Psychology. 2012; 1(3):82-100.

[19] Carmody J, Reed G, Kristeller J, Merriam P. Mindfulness, spirituality, and health-related symptoms. Journal of Psychosomatic Research. 2008; 64(4):393-403. doi: 10.1016/j.jpsychores.2007.06.015 
[20] Kazemian S. [The effectiveness of mindfulness-based cognitive therapy on general health of- self-therapy abusers (Persian)]. Journal of Cognitive and Behavioral Sciences. 2014; 4(1):181-92.

[21] Jahangirpur M, Mousavi V, Khosrojavid M, Salari A, Rezaei S. [The effectiveness of group mindfulness training on depression, hostility and anxiety in individuals with coronary heart disease (Persian)]. Urmia Medical Journal. 2013; 24(9):730-9.

[22] Skinner TC, Roberton T, Allison GT, Dunlop S, Bucks RS. Experiential avoidance, mindfulness and depression in spinal cord injuries: A preliminary study. The Australian Journal of Rehabilitation Counselling. 2010; 16(1):27-35. doi: 10.1375/ jrc.16.1.27

[23] Kazdin AE. Research design in clinical psychology. Boston: Allay and Bacon; 1992.

[24] Keyes CLM, Shmotkin D, Ryff CD. Optimizing wellbeing: The empirical encounter of two traditions. Journal of Personality and Social Psychology. 2002; 82(6):1007-22. doi: 10.1037/0022-3514.82.6.1007

[25] Mikaeily N, Javanmard S. Narimani M. The relationship of perfectionism and type A behavior with psychological wellbeing in staff (Persian). Psychological Researches. 2013; 21(6): 29-39.

[26] Segal ZV, Williams JM, Teasdale JD. Mindfulness-based cognitive therapy for depression. New York: Guilford Press; 2012.

[27] Finlay K. Efficacy of a mindfulness-based intervention for spinal cord injured outpatients with chronic neuropathic pain. Wales: UK Clinical Trial Gatway; 2014. doi: 10.1186/isrctn14165286

[28] Keng S-L, Smoski MJ, Robins CJ. Effects of mindfulness on psychological health: A review of empirical studies. Clinical Psychology Review. 2011; 31(6):1041-56. doi: 10.1016/j. cpr.2011.04.006

[29] Siegel RD. The mindful solution: Everyday practices for everyday problems. New York: Guilford; 2010.

[30] Shapiro SL, Carlson LE, Astin JA, Freedman B. Mechanisms of mindfulness. Journal of Clinical Psychology. 2006; 62(3):373-86. doi: 10.1002/jclp.20237

[31] Hayes SC, Follette VM, Linehan M. Mindfulness and acceptance: Expanding the cognitive-behavioral tradition. New York: Guilford Press; 2004

[32] Hayes SC, Strosahl KD, Wilson KG. Acceptance and commitment therapy: An experiential approach to behavior change. New York: Guilford Press; 1999. 